\title{
Grupo de Tecnologias e Aplicações da Computação (GTAC)
}

\author{
Daniela S.Santana ${ }^{1}$, Carlos H. S. Santos ${ }^{1}$, Wilton M.F. Junior ${ }^{1}$, Ricardo P. Schefer ${ }^{1}$, \\ Gerson N. Carriel ${ }^{1}$
}

\author{
${ }^{1}$ Instituto Federal de São Paulo IFSP -Campus Itapetininga \\ CEP 18202-000 - Itapetininga - SP - Brazil \\ daniela.santana@ifsp.edu.br, santos.chsegmail.com, \\ Wilton.jr@hotmail.com, ricardops05@gmail.com, gerson.carriel@gmail.com
}

O grupo de tecnologias e aplicações da computação GTAC tem como objetivo ser um grupo voltado a tecnologias de informação e comunicação (TIC) para diferentes aplicações. O grupo apesar de recém-criado, já é muito atuante nas frentes de ensino, pesquisa e extensão, tendo recentemente aprovado artigos em revistas e trabalhos em congressos. As pesquisas desenvolvidas pelo grupo são bem diversificadas tendo desde desenvolvimento de jogos a estudos relacionados ao estudo de física no ensino médio.

Alguns trabalhos desenvolvidos pelo grupo de pesquisa serão apresentados abaixo:

Desenvolvimento de histórias em quadrinhos para crianças com câncer, utilizando uma mesa digitalizadora com software INScape. Estudo sobre o ensino de física no ensino médio. (PIBIT)

Os recursos computacionais sendo explorado de forma a auxiliar o processo de ensinoaprendizagem são interessantes quando aos métodos e recursos a serem empregados. Nesse sentido, a construção de técnicas ou métodos para a inserção das tecnologias computacionais do cotidiano escolar é um desafio interessante de ser explorado nos diferentes níveis de ensino e realidades sociais encontradas nessa diversidade brasileira.

Desenvolvimento e utilização de games educacionais, que visa à oferta de oficinas para utilização de jogos educativos para professores e estudantes vinculados às escolas da rede pública de ensino, utilizando uma metodologia baseada em padrões de projetos a desenvolverem jogos simples para computadores e também para que possam levar essa dinâmica de desenvolvimento para seu cotidiano escolar, quando lhe for ofertada a estrutura de trabalho. Essas atividades lúdicas podem ser promovidas com o intuito de promover um processo de ensino-aprendizagem mais descontraído e que motive o jovem para a aprendizagem de conteúdos escolares por meio dos jogos.

Aprendendo Física Através de Modelos Virtuais: O objetivo do projeto é criar alguns exemplos encontrados em livros de física no ensino médio com foco em cinemática. Será utilizado o software Alice dá suporte na criação de animações com modelos 3D, possibilitando aos alunos visualizar e interagir com reproduções virtuais.

Desenvolvimento web sites com ênfase na acessibilidade. As atividades buscam identificar etapas e atividades de ensino que auxiliem os alunos a produzir interfaces para pessoas com deficiências (como deficiência de visão ou motora), não apenas ensinar o aluno a fazer interfaces, mas ter a preocupação de que a acessibilidade deve ser planejada já nas primeiras fases de construção de um websites. (PIBIT) 